\title{
Crime Prevention: The Role of Economic and Social Support
}

\section{Don Weatherburn and Bronwyn Lind}

\begin{abstract}
$A$ ustralia is experiencing a growth in income inequality (Saunders, Stott and Hobbes, 1991; Saunders, 1993a) and progressive spatial concentration of its urban poor (Gregory and Hunter, 1995). Evidence from studies in the United States and Australia suggests that these conditions portend higher rates of crime (Fowles and Merva, 1996; Devery, 1991; Weatherburn and Lind, 1997; Braithwaite, 1979; Weatherburn and Lind, 1998a). In fact they may have done so already. The growth in income inequality that occurred between 1976 and 1991 (Gregory and Hunter, 1995) has since been followed by substantial increases in most categories of recorded crime (Mukherjee and Dagger, 1990). Rates of vehicle theft, break and enter, and robbery in some States of Australia are now as high, if not higher than those in the United States (Australian Bureau of Statistics, 1997; Langan and Farrington, 1998).

The purpose of this article is to discuss how social and economic policy might be used to help reduce crime. We review evidence suggesting that economic and social disadvantage increases crime by decreasing the quality of parenting. We argue on the strength of this evidence that economic and social policy have a role to play in helping to reduce or prevent further growth in crime. In taking up this issue we do not intend to suggest that the traditional methods for controlling crime (for example catching and punishing offenders) have somehow failed. We have been drawn to a discussion of economic and social policy because recent evidence suggests it has a useful supplementary role to play in crime prevention.

It would be nice if our conclusions about the crime prevention value of economic and social policy were founded solely on the results of rigorous experimentation. Unfortunately, for the most part, this is not the case. In the main we shall have to make do with evidence about causes, derived from research employing only statistical controls. This is less than ideal but social, economic and health policy arguments often have to be based on just such evidence. Readers should note, however, that in the interests of space we have been sparing in our citation of evidence. In general we have only cited the most recent research supporting a point rather than all of the studies which might be called upon to support it.
\end{abstract}

Don Weatherburn is Director and Bronwyn Lind is Deputy Director of the New South Wales Bureau of Crime Statistics and Research. 
The discussion is broken into five sections. In the first we review developments in our understanding of the pathways between disadvantage and crime. In the second we discuss the value of measures designed to reduce the economic burden on individual families. In the third we address approaches to reducing the spatial concentration of poverty. In the fourth we consider the role of social support in preventing crime. In the fifth we summarise the argument of preceding sections.

\section{Some Definitions}

Central to our argument is the distinction between 'economic' and 'social' disadvantage. By the term 'economic' disadvantage we mean the disadvantage suffered by those whose income is very low relative to the population in which they live, whether as a result of unemployment, dependence on welfare or employment in a poorly paid job. By the term 'social' disadvantage we mean conditions such as lack of a supportive partner (or no partner at all), responsibility for a large family, physical or social isolation, inadequate or crowded housing, poor education and poor physical and/or mental health.

As we use it, the term 'crime' refers to the offences most commonly reported to police and dealt with by the courts (for example assault, burglary, vehicle theft, robbery, etc.). We exclude from consideration 'white collar' offences such as insider trading, transfer pricing or major fraud because we have no evidence that the causes of involvement in these crimes are similar to those for the more commonly recorded categories of crime. The term 'acquisitive crime' refers to crime committed for material gain (for example burglary or robbery). The term 'non-acquisitive crime' refers to crime for which there is usually no material gain (for example malicious damage to property or assault).

\section{The Effects of Economic and Social Disadvantage on Crime}

Criminologists and economists have often argued that crime is more prevalent among economically disadvantaged groups because it offers a means of overcoming material disadvantage. In the $1960 \mathrm{~s}$ this view fostered the belief that policies designed to reduce disadvantage should help to reduce crime. During the 1970s and 1980s, however, a number of developments combined to undermine scholarly confidence in this assumption.

The first was the apparent failure of the so-called 'War on Poverty' to reduce crime in the United States (Cohen and Felson, 1979). The War on Poverty involved, amongst other things, expanded eligibility for income transfer programs, increased aid to families with dependent children, new or expanded programs such as Medicaid and food stamps, compensatory job training and compensatory schooling. In spite of massive government investment in these programs, between 1960 and 1975 reported rates of robbery, aggravated assault, 
forcible rape, homicide and burglary increased substantially (Cohen and Felson, 1979).

The second development was the failure to observe any consistent positive temporal association between crime and unemployment over two decades of research on the problem (Chiricos, 1987). The third was the discovery that the events and processes which precipitate offending occur well before entry into the labour market and, in many cases before entry into secondary school (Farrington et al., 1990; Loeber and Stouthamer-Loeber, 1986). ${ }^{1}$ The fourth was the discovery that disadvantaged neighbourhoods exhibit both acquisitive and nonacquisitive crime problems (Chiricos, 1987). All these findings appear difficult to reconcile with the idea that crime is committed as a means of overcoming material disadvantage.

These developments prompted some scholars to reject the view that economic disadvantage causes crime (Gottfredson and Hirschi, 1990). Over the last decade, however, it has become increasingly clear that economic disadvantage may be linked to crime, not because it creates a means of overcoming material disadvantage, but because it exerts a disruptive effect on the parenting process. There are essentially two lines of evidence which support this conclusion - one derived from aggregate-level studies of the correlates of child maltreatment and the other derived from studies of individual families.

Aggregate-level studies generally show that poverty remains a significant predictor of the rate of child maltreatment in a neighbourhood even after controls have been introduced for family size, rates of family dissolution, geographic mobility, population age profile and ethnic composition (Chaffin, Kelleher and Hollenberg, 1996). These same studies also generally show that indices of social disadvantage, such as family size and family dissolution, also exert independent positive effects on the rate of child maltreatment.

Studies of individual families have shown that those exposed to economic stress are much more likely to engage in inadequate parenting practices, such as poor supervision of children or erratic, harsh and inconsistent discipline (for example, Sampson and Laub, 1994). These effects generally hold up in the presence of controls for factors such as family size, residential mobility and family dissolution, although these factors also generally exert strong independent adverse effects on the quality of parenting and the strength of the parent-child relationship.

There is a well-established link between poor parenting and juvenile crime. ${ }^{2}$ Juveniles rejected or neglected by their parents, weakly attached to or supervised

\footnotetext{
1 This observation is not inconsistent with the thesis that economic disadvantage increases crime but it is inconsistent with the assumption that it does so solely by creating inducements to offend.

2 Between thitty and sixty per cent of juvenile offenders who come before a Children's Court, however, persist as adults with at least one arrest for a serious offence (Blumstein, Cohen, Roth and Visher, 1986:86). It follows that factors which increase the likelihood of juvenile involvement in crime almost certainly exert an effect on adult involvement in crime.
} 
by them, or exposed to harsh, erratic and inconsistent discipline are much more likely to become involved in crime (Sherman et al., 1997). ${ }^{3}$ These findings hold up in the presence of controls for factors such as IQ and socioeconomic status (Loeber and Stouthamer-Loeber, 1986). In fact much of the relationship between socioeconomic status and crime disappears when controls are introduced for inadequate parenting (Larzelere and Patterson, 1990; Sampson and Laub, 1994; Weatherburn and Lind, 1997).

The adverse impact of poverty is more pronounced when it is accompanied by social stressors, such as the lack of a supportive partner, the presence of a large number of children, depression and parental drug use (Salmelainen, 1996). On the other hand it is less pronounced when parents who are economically disadvantaged can call on a close and strong network of neighbours, friends or relatives for support (Lacharité, Ethier and Couture, 1996). Spatial concentration of disadvantage also appears to make an independent contribution to the delinquency generation process. Braithwaite (1979) observed that disadvantaged juveniles are more likely to become involved in crime if they live in disadvantaged neighbourhoods. Similar findings have been obtained by Weatherburn and Lind (1998).

These findings help explain why the War on Poverty failed to exert any immediate effect on crime and yet why efforts to reduce economic and social disadvantage might still produce a crime reduction dividend. If economic and social disadvantage influence crime via the parenting process then the improvements in economic and social conditions will only influence crime if they increase the quality of parenting. Even then, a decrease in crime will not be observed until the children who benefit from improved family life reach their crime-prone years.

In the next three sections we discuss how one might best go about reducing economic and social stress for the purposes of helping to prevent crime. We begin with the problem of economic stress.

\section{Reducing Economic Stress}

The first line of defence against the problems we have just described has traditionally been the provision of welfare. But every government has to grapple with the problem of how far to extend the provision of welfare. To complicate matters, it has been argued by some that the provision of ready access to welfare actually entrenches poverty.

3 This is not to say that poor parenting is the only cause of juvenile crime. Other factors, such as low IQ and delinquent peer influence have also been implicated. Some of these other factors, however, interact with poor parenting to cause crime. A number of studies, for example, have shown that inadequate parenting increases the risk of association with delinquent peers and that, in turn, increases the risk of involvement in crime (Agnew, 1993). 
Lewis (1968), for example, argued that government welfare created a culture of dependence in which 'slum children [absorb] ... the basic values and attitudes of their subculture and are not psychologically geared to take full advantage of changing conditions or increased opportunities which occur in their lifetime' (Lewis, 1968). Murray (1984) has argued that US Government efforts to reduce poverty actually encouraged it by making it easier for women to have children out of wedlock without the benefit of financial support from a partner. Arguments in support of this conclusion have come in for considerable criticism (for example, Wilson, 1987). Both conservatives and liberals alike, however, now seem to agree that poverty is better tackled through the creation of employment opportunities and incentives than through the provision of welfare (The Economist, 1994; Latham, 1996).

There are good reasons for believing, nonetheless, that economic policy must aim at more than economic growth if it is to be of maximum assistance in reducing crime. There are two reasons for this. Firstly, low-income families that lack strong social supports find it difficult to reconcile the conflicting demands of work and parenting. For this (growing) group of families, entry into the labour market without adequate support is likely to result in a deterioration in the quality of parenting. Secondly, without active labour market intervention and measures to remove poverty traps, economic growth may not do as much as it could to ameliorate the problem of poverty and unemployment. ${ }^{4}$

\section{Parenting and work}

Because the time and energy of individuals are finite resources there is an intrinsic tension between the demands of employment and those of effective parenting. For many households this tension is barely noticeable. For a growing number of househoids where one of the parents is no longer present to provide parenting support or where both parents must work full-time to support the family (Gilding, 1997) the tension between work and parenting is more palpable. Family dissolution, in particular, often results in a substantial drop in income and increased social isolation for the primary caregiver (Harrison, 1993).

Risk factors for child maltreatment and delinquency tend to be cumulative in their effect (Yoshikawa, 1994). The children of sole parents and those where both parents must work full-time to support the family will not inevitably end up young offenders. The tension between employment and competent parenting is most likely to prove criminogenic when a parent's ability to cope with the pressures of child-rearing is already compromised by problems such as poor education, poor mental health, drug dependence, a large family and/or an 4 That is, circumstances where the interaction between tax and social security requirements
leaves some people better off on welfare than in paid employment. 
unsupportive partner or other problems that compromise parental patience and understanding.

Not surprisingly, recognition of these problems has in some quarters prompted nostalgic calls for a return to 'the traditional family' (see Sullivan, 1997), with tax concessions being proposed to encourage carers to stay at home for child-rearing purposes. If tax concessions for 'stay-at-home' parents increase the number of families where one parent (of either gender) is able to remain more fully occupied in child-rearing activity during the early years of a child's life, they are a positive contribution to better parenting. At the same time it would be naive to imagine that tax concessions compensate adequately for the loss of income, social worth or social contact attendant upon giving up paid employment.

If economic growth and the creation of employment opportunities are to be made the means by which we combat poverty, access to affordable but professional childcare is necessary for families whose exposure to economic and/or social stress puts them at risk of child maltreatment and their children at risk of later involvement in crime. The emphasis on professional childcare is important because, although childcare cannot hope to substitute for effective parenting, it should not be seen simply as a means of warehousing children while their parents work. If childcare is to prove of assistance in reducing crime, those who deliver it should aim to reduce the major risk factors associated with later juvenile involvement in crime. In other words, they should aim to improve the child's cognitive and reasoning skills, discourage disruptive and aggressive behaviour, and increase the ability of parents to manage their children. $^{5}$

\section{Labour market programs}

For those low-income families that can satisfactorily negotiate a path between the demands of parenting and those of employment, the critical question is where to find a job. The road to job growth may travel through sustainable economic growth but one frequently remarked upon feature of the Australian economy over the last two decades has been the growth in structural unemployment in spite of sustained economic growth (Chapman, 1997).

Sustained economic growth may eventually eliminate structural unemployment. Poor parenting induced by long-term unemployment, however, may produce effects that are hard to reverse. The first three years of life are critical to child development. Inadequate parenting at this time can produce adverse effects on child behaviour which are hard to erase (Kotulak, 1998). If there are direct ways in which to reduce the long-term unemployment among families with dependent children it would seem prudent to explore them.

5 We discuss these conditions in more detail under the heading of 'The Role of Social Support'. 
Fortunately there is evidence that labour market programs are not only effective in reducing long-term unemployment but can achieve this goal in a revenueneutral way (Piggott and Chapman, 1994).

\section{Taxation policy and other forms of economic support}

Labour market programs are not likely to prove effective in reducing long-term unemployment if the tax system is such as to leave some individuals better off on welfare than they would be in paid employment (Chapman, 1997). Taxation policy can be used to remove such disincentives to work. The interests of crime prevention are not well served, however, if low-paid employment simply ends up replacing social security as a source of poverty among families with young dependent children. While there may be non-economic benefits associated with the switch from welfare to work, the crime prevention benefits of employment are likely to be larger if they are accompanied by a real reduction in the level of poverty on families with dependent children. This is especially true where poverty is exacerbated by factors such as large family size or the absence of a supportive partner.

There are other avenues through which government can provide support to low-income families with young dependent children. The provision of low-cost public housing during the 1980 s appears to have been insufficient to prevent the cost of housing for low-income groups becoming a major factor in the growth in poverty in Australia during that decade (Saunders, 1993b). This suggests a need for strategies to make housing more affordable for low-income families. One obvious way of achieving this goal is to increase the stock of public housing. But there are other ways of achieving the same goal, such as the system of housing vouchers proposed by the current Commonwealth Government.

\section{Approaches to Neighbourhood Poverty}

We argued earlier that the scale of poverty and its geographic concentration exert related, but separate, contributions to the level of crime in a community. In this section we consider ways to reduce the geographic concentration of poverty. Despite the importance of this problem it appears to have been the subject of very little empirical research. Much of what we have to say in this section is of necessity somewhat speculative.

Hughes (1987) has identified development, dispersal and mobility strategies as the three avenues open to government to tackle this problem. Development strategies involve attempts to improve the structure of depressed neighbourhoods through government job creation schemes, improved housing, increased educational opportunities or the creation of 'enterprise zones' (Erickson and Friedman, 1991). The latter essentially involve the creation of incentives for 
business to invest with a view to enhancing job opportunities in areas of concentrated economic and social disadvantage.

Dispersal strategies are designed to encourage disadvantaged people to leave impoverished neighbourhoods. There are three main ways in which this can be accomplished. One option involves creating employment opportunities in areas surrounding a ghetto in the hope that this will prompt its residents to move into such areas. The second option involves providing rent subsidies to residents in ghettos who are willing to move into other neighbourhoods. The third option involves ensuring that public housing is dispersed through areas that are not highly disadvantaged.

Mobility strategies are those designed to provide the residents of ghettos with access to suburban employment opportunities (Hughes, 1987). Among the various initiatives that might be included in a mobility strategy, Hughes has suggested: providing job training to prepare would-be workers for suburban labour markets; providing job information systems to match city workers to suburban employers; restructuring transportation systems to facilitate journeys to work; providing day-care facilities and subsidies for parents of young children; and supplementing the wages of entry-level jobs with a tax credit, which provides a mechanism for supporting low-income workers while delivering that support through employment.

Development and dispersal strategies have been the subject of some criticism in the United States. Development strategies have derisively been referred to as 'Ghetto Gilding' (Kain and Persky, 1969), on the grounds that efforts to improve the quality of life in suburban American ghettos only succeed in encouraging residents to remain in the 'ghetto', therefore making it more difficult to solve ghetto-related problems. The spatial concentration of poverty, Kain and Persky hypothesise, limits access to information about job opportunities and restricts the tax base on which municipal authorities can draw to improve services. They also point out the difficulties involved in ensuring that the jobs created in 'ghettos' actually go to those who reside in them.

It is difficult to gauge the relevance of these criticisms to Australia. The level of poverty is much less pronounced than it is in the United States (Saunders, Stott and Hobbes, 1991). Indeed, there are also very few places in Australia that could fairly be described as 'ghettos', at least as most Americans would understand that term. This suggests that the social problems encountered in Australia's poorer suburbs may be less intractable than those found in the poorest neighbourhoods of the United States. From one point of view, therefore, locating firms in disadvantaged areas might do more to reduce the spatial concentration of disadvantage in Australia than it has in the United States.

Of course, whether firms can or should be induced to locate in disadvantaged areas is very much open to debate. Hunter (1995) has argued that offering inducements to firms to locate in particular areas to deal with a geographic concentration of poverty is inefficient. If the goal is to forestall future growth in 
crime, job creation efficiency may not be the best criterion against which to assess the merits of a particular job creation policy. Perhaps a more salient criticism of development strategies, whether in Australia or elsewhere, is that there is very little evidence governments in a free market economy can significantly influence the location of employment.

As with development, lack of research also makes it difficult to assess the merits of dispersal. There has been only one documented evaluation of an attempt to disperse an entire ghetto (Bushway and Reuter, 1997). While the results of that evaluation appear to have been favourable, Bushway and Reuter maintain that attempts to disperse whole neighbourhoods are likely to be met with resistance from residents being relocated or with opposition from residents of neighbourhoods into which they are being relocated. The experience of attempts to relocate aboriginal residents in 'the Block' in Redfern (Sydney) provide eloquent testimony to the validity of this argument.

One way in which dispersal might be accomplished without provoking resistance is through housing policy. Funding for Australian public housing has tended in the past to encourage forms of public housing (for example estates, high-rise apartments) which result in high population densities of economicallystressed individuals and families. Experience with crime problems on public housing estates suggests that this is an outcome worth avoiding and that there are ways in which it can be done. The provision of rent subsidies or the introduction of a requirement that developers include a component of new lowcost housing as part of the development consent process, for example, could be used to limit the spatial concentration of disadvantage. ${ }^{6}$

The great advantage mobility strategies have over development and dispersal is that they reinforce natural market processes. We have already argued in favour of some mobility strategies (for example tax credits, job training and subsidised access to professional childcare). Others, unfortunately, such as improved transportation and job information networks are probably more relevant to the United States than to Australia. Australians generally have access to fairly effective job information networks and extensive and heavily subsidised public transport connecting them to city and urban job opportunities.

On balance, a priori considerations seem to favour mobility and dispersal as strategies for tackling the spatial concentration of disadvantage over development strategies. Given the significance of the problem and the current state of research on its solution, however, governments would be well advised to consider and evaluate all reasonable proposals for reducing the spatial concentration of disadvantage.

6 We are grateful to one of our anonymous reviewers for this suggestion. 


\section{The Role of Social Support}

Since the effects of economic and social stress are ameliorated when a parent can obtain support in parenting from friends, neighbours and relatives, we would expect programs which seek to provide this sort of support to be effective in reducing the risk of delinquency, and they are. A number of rigorously conducted randomised trials ${ }^{7}$ have shown that perinatal and adolescent support designed to prevent inadequate parenting; discourage disruptive behaviour by young children; improve their cognitive ability; increase family harmony and strengthen the parent-child bond reduces the long-term risk that juveniles will become involved in crime. Such support has also been shown to produce a range of ancillary benefits, including better labour market outcomes and reduced likelihood of teenage pregnancy (Yoshikawa, 1994).

The crime prevention benefits of social support are substantial. In one fifteen-year follow-up study of a home visitation program, adolescents whose mothers received nurse home visitation services were 55 per cent less likely to have been arrested and 80 per cent less likely to have been convicted of a crime than their control group counterparts (Olds, Hill and Rumsey, 1998). Home visiting programs are also relatively inexpensive. The nurse home visitation program developed by Olds and his colleagues costs an estimated $\$ 3,200$ per family per year during the first three (start-up) years and about $\$ 2,800$ per family per year after that. ${ }^{8}$ Karoly et al. (1998) estimate that the program will eventually produce savings accruing from reduced crime, welfare expenditure, health care costs and increased tax revenue, which are four times higher than the original cost of the program.

There are signs of growing interest on the part of Australian governments in social support as a crime prevention measure (NSW Legislative Council, 1998). Those contemplating such support, however, need to ensure that the program being implemented either reflects that which has been shown to work or is subjected to rigorous and independent evaluation. Parenting programs have become a multi-million dollar business in the United States. Few of the programs on offer have been rigorously evaluated and some actually discourage the use of parenting techniques (for example withdrawal of privileges) which are known to be effective in managing disruptive behaviour (Kumpfer and Alvarado, 1998). This fact alone is ample evidence of the need for caution in pursuing social support with a view to crime prevention.

7 It is important to emphasise the fact that these were genuine randomised trials. The families participating in them had all elected to participate but some groups were simply provided with financial inducements and/or free health services while others were given the benefit program being evaluated.

8 This compares with an average annual cost of housing a prisoner in medium security in New South Wales of nearly $\$ 55,000$ (NSW Department of Corrective Services, 1996/97:11). 
Further research is also needed on the minimum requirements for an effective social support program, in terms of content, method of administration and duration. Social support may be cheaper per family than imprisonment per incarcerated offender but this does not mean social support is invariably more cost-effective as a crime control strategy. To be maximally effective, social support programs must be targeted at all families whose children are at risk of involvement in crime. Many children identified as potential offenders, however, will never actually become involved in crime. By contrast, imprisonment can always be targeted at known offenders. This means that many more individuals must be targeted to achieve a given aggregate crime prevention effect through social support programs than have to be targeted to obtain the same effect (via incapacitation) from imprisonment (Greenwood, Model and Rydell, 1995).

A second significant problem for policy in the domain of social support concerns what might be called the 'targeting-stigma dilemma'. In theory the most cost-effective way to introduce social support programs to prevent crime is to target them at groups in the community where the risk of delinquency is highest. Targeted services, however, can sometimes be stigmatising and never more so than when they are designed to prevent children becoming offenders. Common sense suggests that services which carry a social stigma attached to them are less likely to be taken up. The smaller the number of 'at-risk' families who avail themselves of social support services the less effective they are going to be in preventing crime.

There is a variety of ways of dealing with this problem. Because they confer other benefits, social support programs do not have to be presented specifically as crime prevention measures. Some components of social support (for example advice on child nutrition) are relatively inexpensive and might be worth offering on a universal basis. One can also target social support services not at particular families but at particular localities. Such 'place' targeting is probably less stigmatising than 'family' targeting. It may also prove more effective. If locations are treated as the unit of service provision it also becomes possible to marshal more effectively the resources of local communities and municipal authorities in the delivery of programs. None of this is to pre-judge the most efficient and effective way of delivering social support. This remains an empirical question and one badly in need of further research.

Perhaps the most important challenge facing the use of social support programs to prevent crime in Australia is the need to link such programs to existing government and non-government child protection services and evaluate them against population-level leading indicators of crime (for example rates of child maltreatment). It is one thing to demonstrate in the somewhat rarefied atmosphere of an experiment that a program administered by highly trained and motivated professionals is effective in preventing crime amongst a target group of children. It is quite another to demonstrate that the program remains efficacious when run by a less well paid, less well trained and less motivated 
staff in an agency charged with responsibility for preventing child neglect and abuse among thousands of families.

\section{Conclusion}

The purpose of this paper has been to discuss how economic and social support might be used to help reduce crime. Their potential in this regard arises from the fact that economic and social disadvantage appear to increase crime through the disruptive effects they exert on the parenting process.

Although there is no direct evidence that economic support can be used to reduce crime, there are good empirical reasons for believing that economic support targeted at the right families over the long term may prove helpful in reducing or preventing crime. We have argued that the forms of economic support best calculated to achieve this end are those which improve access for low-income families to professional childcare, which reduce the level of longterm unemployment, which remove poverty traps and which make housing more affordable. These are plausible hypotheses but they need to be empirically tested.

Because living in a low-income neighbourhood appears to strengthen the relationship between family poverty and crime, it is also worth considering options for reducing or limiting growth in the spatial concentration of economic disadvantage. This is a more difficult goal to achieve because so little research has been conducted on the best means of achieving it. The most promising strategies would seem to be those which aim to overcome the natural obstacles to employment created by living in areas of concentrated disadvantage. There are, however, other options, including those which seek to disperse economic disadvantage through public housing policy.

The scope for reducing crime through social support is clearer. A number of rigorously evaluated programs designed to provide social support have been shown to reduce the long-term risk of serious involvement in crime. They also produce a range of ancillary benefits, including better labour market outcomes and rates of reduced teenage pregnancy. Studies in the United States indicate that the economic benefits of investment in social support programs substantially exceed their cost.

One of the problems facing social support programs, however, is the 'freerider' problem. While it is possible to identify families whose children are at risk of involvement in crime, our ability to predict this outcome is far from perfect. If social support programs are targeted at all disadvantaged families many will end up receiving the program without benefiting from it. We can reduce the number of 'free-riders' by employing other information bearing on risk (that is marital status, number of children, household crowding). Restricting access to social support programs to families with these 
characteristics, however, may only serve to stigmatise them. They may result in less than optimal program utilisation.

More work also needs to be done in determining the minimum requirements for a successful social support program and in assessing the best means of embedding them in the routine practice of agencies involved in child welfare. The former issue obviously has a bearing on the extent to which governments can provide access to social support programs for all those who stand to benefit from them. The latter is important because, to date, successful programs have all been run as relatively small operations staffed by highly trained and motivated staff. We cannot be sure that programs which have been shown to be efficacious will remain effective when rolled out on a much larger scale and managed by less well trained and less highly motivated staff dealing with much larger caseloads.

The provision of economic and social support should be seen as an important way of preventing or limiting future increases in crime rather than as a direct means of bringing about a reduction in crime in the short-term. It is too late to change the behaviour of the existing population of offenders through policies that aim to improve the quality of parenting. This said, one ought not to underestimate the potential of economic and social policy to reduce crime. Data in Weatherburn and Lind (1997) suggest that reducing the number of families whose incomes are below $\$ 16,000$ per annum by 1,000 would result in at least 141 fewer juveniles involved in crime. A similar reduction in the number of neglected children would result in 256 fewer juveniles involved in crime. Considering the volume of crime generated by offenders during the course of a criminal career these findings strongly reinforce the need for further work on the scope for reducing crime through social and economic policy.

\section{References}

Agnew, R. (1993), 'Why Do They Do It? An Examination of the Intervening Mechanisms between 'Social Control' Variables and Delinquency', Journal of Research in Crime and Delinquency 30(3):245-66.

Australian Bureau of Statistics (ABS) (1997), Crime and Safety, New South Wales, April 1997, Catalogue No. 4509.1, Sydney.

Blumstein, A., J. Cohen, J. Roth and C. Visher (1986), Criminal Careers and Career Criminals, National Academy Press, Washington DC.

Braithwaite, J. (1979), Inequality, Crime and Public Policy, Routledge and Kegan Paul, London.

Bushway, S. and P. Reuter (1997), 'Labor markets and Crime Risk Factors' ch. 9 in L. Sherman, D. Gottfredson, D. MacKenzie, J. Eck, P. Reuter and S. Bushway, Preventing Crime: What Works, What Doesn't, What's Promising, A Report to the United States Congress, prepared for the National Institute of Justice, Washington DC. 
Chaffin, M., K. Kelleher and J. Hollenberg (1996), 'Onset of Physical Abuse and Neglect: Psychiatric, Substance Abuse, and Social Risk Factors from Prospective Community Data', Child Abuse and Neglect 20(3):191-203.

Chapman, B. (1997), 'Long-Term Unemployment and Labour Market Programs', prepared for the Industry Commission Workshop, Changing Labour Markets - Prospects for Productivity Growth, Melbourne, 20-21 February, Centre for Economic Policy Research, Research School of Social Sciences, Australian National University, Canberra.

Chiricos, T. (1987), 'Rates of Crime and Unemployment: An Analysis of Aggregate Research Evidence', Social Problems 34(2):187-212.

Cohen, L. and M. Felson (1979), 'Social Change and Crime Rate Trends: A Routine Activity Approach', American Sociological Review 44:588-608.

Devery, C. (1991), Disadvantage and Crime, NSW Bureau of Crime Statistics and Research, Sydney.

Erickson, R. and S. Friedman (1991), 'Comparative Dimensions of State Enterprise Zone Policies', in R. Green (ed.), Enterprise Zones: New Dimensions in Economic Development, Sage Focus Edition, Newbury Park, California.

Farrington, D., R. Loeber, D. Elliott, J. Hawkins, D. Kandel, M. Klein, J. McCord, D. Rowe and R. Tremblay (1990), 'Advancing Knowledge about the Onset of Delinquency and Crime', pp. 283-342 in B. Lahey and A. Kazadin (eds), Advances in Clinical Child Psychology, vol. 13, Plenum Press, New York.

Fowles, R. and M. Merva (1996), 'Wage Inequality and Criminal Activity: An Extreme Bounds Analysis for the United States, 1975-1990', Criminology 34(2):163-82.

Gilding, M. (1997), Australian Families: A Comparative Perspective, Longman, Melbourne.

Gottfredson, M. and T. Hirschi (1990), A General Theory of Crime, Stanford University Press, Stanford.

Greenwood, P., K. Model and C. Rydell (1995), The Cost-Effectiveness of Early Intervention as a Strategy for Reducing Violent Crime, The RAND Corporation, Santa Monica.

Gregory, R. and B. Hunter (1995), The Macro Economy and the Growth of Ghettos and Urban Poverty in Australia, Centre for Economic Policy Research, Australian National University, Canberra (Discussion Paper No. 325).

Harrison, M. (1993), 'Patterns of Maintenance Payment Over Time', pp. 116-34 in K. Funder, M. Harrison and R. Weston (eds), Settling Down: Pathways of Parents After Divorce, Australian Institute of Family Studies, Commonwealth of Australia, Canberra.

Hughes, M. (1987), 'Moving Up and Moving Out: Confusing Ends and Means about Ghetto Dispersal', Urban Studies 24:503-17.

Hunter, B. (1995), Changes in the Geographic Dispersion of Urban Employment in Australia: 1976-1991, Unpublished Ph.D. thesis, Australian National University, Canberra.

Kain, J. and J. Persky (1969), 'Alternatives to the Gilded Ghetto', The Public Interest 14:74-87. 
Karoly, L., S. Everingham, J. Hoube, R. Kilburn, C. Rydell, M. Sanders and P. Greenwood (1988), Investing in Our Children: What We Know and Don't Know about the Costs and Benefits of Early Childhood Interventions, MR-898, The RAND Corporation, Santa Monica.

Kotulak, R. (1998), 'Inside the Brain: Revolutionary Discoveries of How the Mind Works', Preventative Medicine 27:246-7.

Kumpfer, K. and R. Alvarado (1998), 'Effective Family Strengthening Interventions', Juvenile Justice Bulletin, Office of Juvenile Justice and Delinquency Prevention, Office of Justice Programs, US Department of Justice, Washington DC.

Lacharité, C., L. Ethier, and G. Couture (1996), 'The Influence of Partners on Parental Stress of Neglectful Mothers', Child Abuse Review 5:18-33.

Langan, P. and D. Farrington (1998), Crime and Justice in the United States and in England and Wales, 1981-96, Bureau of Justice Statistics, Office of Justice Programs, US Department of Justice, Washington DC.

Larzelere, R. and G. Patterson (1990), 'Parental Management: Mediator of the Effect of Socioeconomic Status on Early Delinquency', Criminology 28(2):301-23.

Latham, M. (1996), Making Welfare Work, Centre for Independent Studies, Sydney.

Lewis, O. (1968), 'The Culture of Poverty', pp.187-200 in D. Moynihan (ed.), On Understanding Poverty: Perspectives from the Social Sciences, Basic Books, New York.

Loeber, R. and M. Stouthamer-Loeber (1986), 'Family Factors as Correlates and Predictors of Juvenile Conduct Problems and Delinquency', pp. 29-149 in M. Tonry and N. Morris (eds), Crime and Justice: An Annual Review of Research, vol. 7, University of Chicago Press, Chicago.

Mukherjee, S. and D. Dagger (1990), The Size of the Crime Problem in Australia, second edition, Australian Institute of Criminology, Canberra.

Murray, C. (1984), Losing Ground: American Social Policy, 1950-1980, Basic Books, New York.

NSW Department of Corrective Services (1997), Annual Report 1996/97, Sydney.

NSW Legislative Council (1998), Proceedings of the Conference on Crime Prevention through Social Support, Standing Committee on Law and Justice, Sydney (Report No. 11).

Olds, D. P. Hill and E. Rumsey (1998), 'Prenatal and Early Childhood Nurse Home Visitation', Juvenile Justice Bulletin, Office of Juvenile Justice and Delinquency Prevention, Office of Justice Programs, US Department of Justice, Washington DC.

Piggott, J. and B. Chapman (1995), 'Costing the Job Compact', The Economic Record 71(215):313-28.

Salmelainen, P. (1996), Child Neglect: Its Causes and its Role in Delinquency, NSW Bureau of Crime Statistics and Research, Sydney (Crime and Justice Bulletin No. 33).

Sampson, R. and J. Laub (1993), Crime in the Making: Pathways and Turning Points Through Life, Harvard University Press, Cambridge, Massachusetts. 
Sampson, R. and J. Laub (1994), 'Urban Poverty and the Family Context of Delinquency: A New Look at Structure and Process in a Classic Study', Child Development 65:523-40.

Saunders, P., H. Stott and G. Hobbes (1991), 'Income Inequality in Australia and New Zealand: International Comparisons and Recent Trends', Review of Income and Wealth, Series 37(1):63-79, March.

Saunders, P. (1993a), 'Longer Run Changes in the Distribution of Income in Australia', The Economic Record 69(207):353-66.

Saunders, P. (1993b), Economic Adjustment and Distributional Change: Income Inequality in Australia in the Eighties, Social Policy Research Centre, University of New South Wales, Sydney (Discussion Paper No.47).

Sherman, L., D. Gottfredson, D. MacKenzie, J. Eck, P. Reuter and S. Bushway (1997), Preventing Crime: What Works, What Doesn't, What's Promising, Office of Justice Programs, US Department of Justice, Washington DC.

Sullivan, L. (1997), Rising Crime in Australia, Centre for Independent Studies, Policy Monograph 39 , Sydney.

The Economist, (1994), Welfare Reform in America, pp. 19-21, 18-24 June.

Weatherburn, D. and B. Lind (1997), Social and Economic Stress, Child Neglect and Juvenile Delinquency, NSW Bureau of Crime Statistics and Research, Sydney.

Weatherburn, D. and B. Lind (1998), 'The Developmental Antecedents of Crime-Prone Neighbourhoods', Paper delivered at the National Child Protection Conference held at the Masonic Centre, Sydney, 4-5 May.

Wilson, W. (1987), The Truly Disadvantaged: The Inner City, the Underclass, and Public Policy, University of Chicago Press, Chicago.

Yoshikawa, H. (1994), 'Prevention as Cumulative Protection: Effects of Early Family Support and Education on Chronic Delinquency and its Risks', Psychological Bulletin, 115(1):28-54.

Our thanks to two anonymous referees and to Dr Ruth Lawrence Karski for their helpful comments on an earlier draft of this article. 